\title{
IMPLEMENTASI MODEL PENGEMBANGAN INSTITUSI MELALUI USAHA KESEHATAN GIGI SEKOLAH (UKGS) BINAAN SEBAGAI LAHAN PRAKTIK KERJA LAPANGAN (PKL) JURUSAN KESEHATAN GIGI POLTEKKES KEMENKES MANADO
}

\author{
I Ketut Harapan', Jean Henry Raule ${ }^{2}$, Maxi Alow ${ }^{3}$ \\ 1,2,3) Jurusan Keperawatan Gigi Poltekkes Kemenkes Manado Jl.RW Monginsidi Malalayang II Manado \\ Email : iketutharapan@gmail.com
}

\begin{abstract}
ABSTRAK
Pendahuluan : rogram pemeliharaan kesehatan gigi yang dilaksanakan di sekolah melalui UKGS belum dapat merubah perilaku menggosok gigi siswa menjadi lebih baik dan benar, karena hanya dilaksanakan satu kali dalam satu tahun. Kebiasaan dalam memelihara kesehatan gigi dan mulut dapat diawali melalui pembentukan perilaku sejak dini, dimana masa yang paling tepat untuk menanamkan nilai nilai guna membentuk perilaku positif adalah di sekolah. Metode : Metode R\&D merupakan salah satu proses penelitian dalam mengembangkan suatu produk baru atau menyempurnakan produk yang telah ada dan dapat dipertanggung jawabkan. Jenis penelitian deskriptif analitik pretest dan posttest dengan teknik purposive sampling di SD Katolik St. Theresia Manado sebagai sekolah binaan dan SD GMIM 20 Manado sebagai sekolah kelompok control. Hasil : Hasil validitas expert ahli menunjukan bahwa nilai $p$-value $=0.020$, yang artinya model Pengembangan Institusi Melalui Usaha Kesehatan Gigi Sekolah binaan layak sebagai model lahan praktek Jurusan Kesehatan Gigi Manado. Revitalisasi UKGS dapat dilakukan melalui upaya inovatif dengan penanganan kasus sesuai kompetensi dan dirujukan ke klinik Jurusan Kesehatan Gigi Manado, serta pelatihan dokter kecil. uji statistik menggunakan uji Wilcoxon didapatkan nilai Asymp. Sig(2 tailed $)<0,000$ berarti ada pengaruh dengan metode sekolah binaan terhadap indeks kebersihan gigi dan mulut (OHI-S) siswa. Kesimpulan Implementasi model pengembangan institusi melalui UKGS Binaan layak sebagai program pelaksanaan PKL mhs Jurusan Kesehatan Gibi Poltekkes Manado. Implementasi modul pengembangan institusi melalui UKGS binaan efektif meningkatkan pengetahuan, sikap dan keterampilan dokter kecil di sekolah SD Katolik Santa Theresia.
\end{abstract}

Kata Kunci : Implementasi, Model, Pengembangan dan UKGS Binaan

\begin{abstract}
Introduction: the dental health maintenance program implemented in schools through the UKGS has not been able to change students' teeth brushing behavior to be better and correct, because it is only implemented once a year. The habit of maintaining dental and oral health can be initiated through early behavior formation, where the most appropriate time to instill values in order to form positive behavior is at school. Method: The R\&D method is one of the research processes in developing a new product or perfecting an existing and accountable product. This type of research is descriptive analytic pretest and posttest with purposive sampling technique at SD Catholic St. Theresia Manado as a target school and SD GMIM 20 Manado as a control group school. Results: The results of the validity of the expert experts showed that the $p$-value $=0.020$, which means that the model of Institutional Development through the Dental Health Business of the assisted schools is feasible as a model for the practice area of Manado Dental Health Department UKGS revitalization can be done through innovative efforts by handling cases according to competence and referral to the Manado Dental Health Department clinic, as well as training for little doctors. statistical tests using the Wilcoxon test obtained Asymp values. Sig ( 2 tailed) $<0.000$ means that there is an influence with the target school method on the dental and oral hygiene index (OHI-S) of students. Conclusion : The implementation of the institutional development model through UKGS is feasible as a PKL implementation program for students of the Gibi Health Department of the Manado Health Polytechnic. The implementation of the institutional development module through the assisted UKGS
\end{abstract}


has effectively increased the knowledge, attitudes and skills of the little doctors in Santa Theresia Catholic Elementary School.

Keywords: Implementation, Model, Development and Fostered UKGS

\section{PENDAHULUAN}

Program Usaha Kesehatan Gigi sekolah maupun program pelayanan kesehatan gigi dan mulut yang dicanangkan pemerintah Indonesia dan dunia Internasional belum membuahkan hasil, terbukti bahwa tidak ada satu negarapun yang terbebas dari karies gigi ${ }^{(6)}$. Berdasarkan Riskesdas 2013 kecenderungan masyarakat yang mengalami masalah kesehatan gigi dan mulut sebesar $25,9 \%$ dari jumlah tersebut yang menerima perawatan hanya $31,1 \%$. Masalah kesehatan gigi pada anak sekolah dasar di Indonesia pada tahun 2018 sebesar 57,6\% penduduk, di Provinsi Sulawesi Utara, memiliki angka masalah kesehatan gigi dan mulut diatas rata-rata nasional diatas $60 \%$, dan angka masyarakat penerima perawatan dan pengobatan dari tenaga medis (terapis gigi dan mulut, dokter gigi atau dokter gigi spesialis) tergolong rendah hanya mencapai $12,3 \%{ }^{(4)}$.

Masalah kesehatan gigi diatas, jauh dari harapan untuk mencapai tarjet jangka panjang Kementerian Kesehatan yaitu tahun 2020: angka bebas karies gigi (gigi bercampur) umur 6 tahun 50\%, angka bebas karies gigi kelas 6 sebesar 70\%, DMF-T usia 12 tahun $\leq 1$, PTI sebesar 50\% dan angka dentally fit kelas 6 sebesar $85 \%$. Target tahun 2030 Indonesia bebas karies ${ }^{(8)}$. Masalah kesehatan gigi di Indonesia bukan hanya menjadi masalah pemerintah, akan teapi menjadi tanggung jawab setiap komponen masyarakat termasuk institusi pendidikan kesehatan yang merupakan tangan panjang kementerian kesehatan dalam mencetak sumber data manusia kesehatan. Jurusan Kesehatan Gigi Poltekkes Kemenkes Manado, merupakan pelaksana teknis penyelenggara pendidikan terapis gigi dan mulut yang memiliki kompetensi promotif dan preventif kesehatan gigi. Melalui tridharma perguruan tinggi, Jurusan Kesehatan Gigi dapat berperan aktif membantu kementerian kesehatan dalam mengatasi masalah kesehatan gigi dan mewujudkan Indonesia bebas karies tahun 2030 dengan melakukan revitalisasi Usaha Kesehatan Gigi Sekolah (UKGS) inovatif melalui sekolah dasar binaan.

Penelitian ini bertujuan untuk 1). Membuat rancang bangun implementasi model pengembangan institusi melalui Usaha Kesehatan Gigi Sekolah (UKGS) binaan sebagai lahan Praktik Kerja Lapangan (PKL) Jurusan Kesehatan Gigi Poltekkes Kemenkes Manado, 2). Menganalisis efektifitas implementasi model pengembangan institusi melalui usaha kesehatan gigi sekolah binaan sebagai lahan praktik kerja lapangan lulusan Jurusan Kesehatan Gigi Poltekkes Kemenkes Manado.

\section{METODOLOGI}

Metode yang digunakan dalam penelitian ini adalah Research and Development (R\&D), dengan desain penelitian quasy-experimental dengan rancangan pretest and posttest control group design, dan yang memungkinkan peneliti dapat menguji perubahan-perubahan yang terjadi setelah adanya eksperimen ${ }^{(3)}$.

Variable penelitian yaitu indeks DMF-T pada gigi dewasa dihitung berdasarkan jumlah gigi yang terkena karies, ditandai dengan adanya suatu kavitas (lubang), yang ditentukan berdasarkan adanya sangkutan pada sonde (sondasi) pada kavitas tersebut. Secara visual, ditandai oleh warna coklat sampai dengan hitam (Decay), gigi yang hilang karena karies (Missing), jumlah gigi yang sudah di tambal (Filling). Variable indeks def-t diperikasa pada gigi sulung dihitung berdasarkan jumlah gigi yang terkena karies, ditandai dengan adanya suatu kavitas (lubang), yang ditentukan berdasarkan adanya sangkutan pada sonde 
(sondasi) pada kavitas tersebut. Secara visual, ditandai oleh warna coklat sampai dengan hitam (decay), gigi yang indikasi untuk dicabut karena karies

gigi (indicated for extraction), jumlah gigi yang sudah di tambal (filling).

Sampel dalam penelitian dibagi menjadi 3

kelompok, antara lain:

a. Sampel I: sampel untuk tahap pengumpulan informasi dengan purposive sampling berjumlah 4 orang terdiri dari unsur dinas kesehatan, pihak puskesmas wilayah kerja, kepala sekolah dan guru UKS

b. Sampel II: Berjumlah 60 siswa dengan teknik purposive sampling terdiri dari 30 siswa dari SD Binaan kelas 3 dan 4 dan 30 siswa kelas 3 dan 4 pada SD pada kelompok kontrol.

Analisis data pada penelitian ini menggunakan mix methode yaitu data dianalisis secara diskriptif dan analitik, yang dijabarkan sebagai berikut: Diskriptif, data pengumpulan informasi yang diperoleh melalui wawancara maupun kajian literature akan dianalisis secara diskriptif dengan membuat kesimpulan dan rekomendasi yang hasilnya akan dijadikan bahan kajian dalam penyusunan rancang bangun model. Subjek dalam analisis kualitatif dimaksudkan untuk menggali informasi dan data lebih mendalam atas rumusan masalah yang telah disusun. Dalam penelitian ini yang menjadi informan kunci adalah guru pembina UKGS, tim pembina UKGS kota atau tim pembina UKGS Puskesmas, kepala sekolah.

\section{HASIL}

\section{Pengumpulan Informasi}

Pada tahap pengumpulan informasi, data diperoleh melalui wawancara kepada Dinas Kesehatan, Dinas Pendidikan, Kepala Sekolah, Kepala Puskesmas, Guru Pembina UKGS (Guru Penjas).

Tabel 1. Deskripsi jawaban terhadap pertanyaan : bagaimana program kesehatan gigi dan mulut yang sudah dilaksanakan di sekolah dasar?

\begin{tabular}{|c|c|c|}
\hline Responden & Jawaban & Kesimpulan \\
\hline $\begin{array}{l}\text { Dinas } \\
\text { Kesehatan }\end{array}$ & 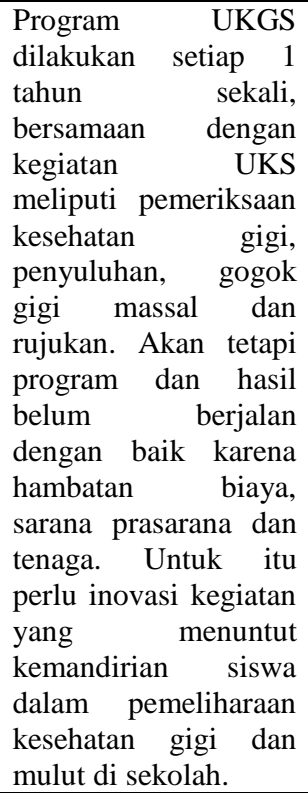 & \multirow{4}{*}{$\begin{array}{c}\text { Program } \\
\text { kesehatan gigi } \\
\text { dan mulut pada } \\
\text { anak sekolah } \\
\text { dasar dilakukan } \\
\text { melalui program } \\
\text { UKGS setiap 1 } \\
\text { tahun sekali.Hal } \\
\text { tersebut } \\
\text { disebabkan } \\
\text { karena } \\
\text { keterbatasan } \\
\text { sarana, pasarana } \\
\text { dan anggaran, } \\
\text { sehingga perlu } \\
\text { inovasi } \\
\text { pengembangan } \\
\text { program } \\
\text { kesehatan gigi di } \\
\text { sekolah. }\end{array}$} \\
\hline $\begin{array}{l}\text { Dinas } \\
\text { Pendidikan }\end{array}$ & $\begin{array}{lr}\text { Pada sekolah } & \text { dasar } \\
\text { program } & \text { kesehatan } \\
\text { gigi dan } & \text { mulut } \\
\text { dilkukan } & \text { melalui } \\
\text { program } & \text { UKGS } \\
\text { meliputi pemeriksaan } \\
\text { gigi, menggosokk gigi } \\
\text { bersama, ran } \\
\text { sosialisasi penyuluhan } \\
\text { berbarengan dengan } \\
\text { penyampaian } & \text { tentang } \\
\text { PHBS. }\end{array}$ & \\
\hline $\begin{array}{l}\text { Kepala } \\
\text { Puskesmas }\end{array}$ & $\begin{array}{lr}\text { Kesehatan gigi dan } \\
\text { mulut } & \text { sudah } \\
\text { dilaksanakan } & \text { di } \\
\text { sekolah tetapi hanya } 1 \\
\text { kali dalam 1 tahun } \\
\text { bersamaan dengan } \\
\text { kegiatan UKS. Karena } \\
\begin{array}{lr}\text { keterbatasan tenaga } \\
\text { dan anggaran. }\end{array} \\
\end{array}$ & \\
\hline $\begin{array}{l}\text { Kepala } \\
\text { sekolah }\end{array}$ & 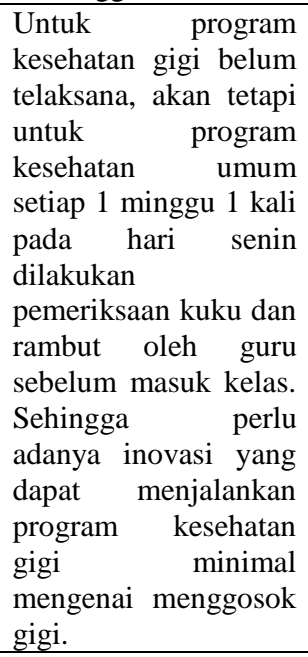 & \\
\hline Guru & $\begin{array}{lr}\begin{array}{l}\text { Program yang } \\
\text { dilakukan }\end{array} & \text { dariah } \\
\text { puskesmas } & \text { berupa } \\
\end{array}$ & \\
\hline
\end{tabular}




\begin{tabular}{|l|l|}
\hline & penyuluhan dan \\
praktik menggosok \\
gigi. Namun praktik \\
menggosok gigi tidak \\
terlaksanar secara \\
continue rarena \\
praktik hanya \\
dilakukan sekali dan \\
untuk sarana sikat, \\
pasta, gelas kumur \\
yang tidak tersedia di \\
sekolah.
\end{tabular}

Hasil wawancara kepada responden terhadap pertanyaan : "bagaimana program kesehatan gigi dan mulut yang sudah dilaksanakan di sekolah dasar ?"dapat disimpulkan bahwa Program kesehatan gigi dan mulut pada anak sekolah dasar dilakukan melalui program UKGS setiap 1 tahun sekali. Hal tersebut disebabkan karena keterbatasan sarana, pasarana dan anggaran, sehingga perlu inovasi pengembangan program kesehatan gigi di sekolah.

\section{Validasi Ahli Dan Revisi}

\section{A. Hasil validasi expert}

Tabel 2. Uji Statistik Validasi Ahli model Pengembangan Institusi Melalui Usaha Kesehatan Gigi Sekolah (UKGS) Binaan Sebagai Lahan Praktik Kerja Lapangan (PKL) dan Upaya Penyerapan Lulusan Jurusan Kesehatan Gigi Poltekkes Kemenkes Manado

\begin{tabular}{cccc}
\hline \multicolumn{4}{l}{ Validitas Ahli } \\
\hline & $\mathbf{N}$ & $\mathbf{f}(\%)$ & p-value \\
\hline $\begin{array}{c}\text { Relevan } \\
\text { Tidak } \\
\text { relevan }\end{array}$ & 10 & 100 & 0.020 \\
\hline
\end{tabular}

*Intraclass correlation coefficient

Hasil validitas expert ahli menunjukan bahwa nilai $p$-value $=0.020$, yang artinya model Pengembangan Institusi Melalui Usaha Kesehatan Gigi Sekolah (UKGS) binaan layak sebagai model Lahan Praktik Kerja Lapangan (PKL) Jurusan Kesehatan Gigi Poltekkes Kemenkes Manado.

\section{B. Uji Coba Produk/Model}

Uji model Pengembangan Institusi Melalui Usaha Kesehatan Gigi Sekolah (UKGS) binaan sebagai Lahan Praktik Kerja Lapangan (PKL) Jurusan Kesehatan Gigi Poltekkes Kemenkes Manado untuk membentuk perilaku menggosok gigi siswa sekolah dasar menggunakan desain quasy-experimental dengan rancangan pretest and posttest control group design. Uji coba model dilaksanakan mulai bulan September 2019 sampai dengan bulan November 2019 pada SD Katolik St. Theresia sebagai kelompok intervensi dan SD GMIM 20 Manado sebagai kelompok kontrol.

a. Distribusi frekuensi pemeriksaan OHIS awal dan akhir pada kelompok kontrol pada tabel 3 dibawah ini :

Tabel 3 Distribusi frekuensi OHIS awal dan akhir

\begin{tabular}{clcc}
\hline \multirow{2}{*}{ No } & Nilai OHIS & N & Persentase \\
\cline { 2 - 4 } & Pre Test & & \\
\hline 1 & Baik & 0 & 0 \\
2 & Sedang & 17 & 56.7 \\
3 & Buruk & 13 & 43.3 \\
& Post Test & & \\
\hline 1 & Baik & 0 & 0 \\
2 & Sedang & 12 & 40 \\
3 & Buruk & 18 & 60 \\
\hline & Total & 30 & 100 \\
\hline
\end{tabular}

Tabel 3 diatas menunjukkan bahwa pemeriksaan nilai OHIS awal didapatkan persentase terbesar pada kategori sedang sebanyak 17 responden $(56,7 \%)$, buruk sebanyak 13 responden (43,3\%). Setelah beberapa hari dilakukan pemeriksaan kembali tanpa diberikan tindakan, didapatkan persentase dengan kategori sedang sebanyak 12 responden (40\%), buruk sebanyak 18 responden $(60 \%)$

b. Distribusi frekuensi pemeriksaan nilai DMF-T awal dan akhir pada sekolah binaan pada tabel 4 dibawah ini : 
Tabel.4 Distribusi frekuensi niali DMF-T awal dan akhir

\begin{tabular}{clcc}
\hline \multirow{2}{*}{ No } & Nilai DMF-T & N & Persentase \\
\cline { 2 - 4 } & Sebelum & & \\
\hline 1 & D & 74 & 97.4 \\
2 & M & 0 & 0 \\
3 & F & 2 & 2.6 \\
& Sesudah & & \\
\hline 1 & D & 0 & 0 \\
2 & M & 0 & 0 \\
3 & F & 76 & 100 \\
\hline & Total & 76 & 100
\end{tabular}

Dari tabel 4 diatas menunjukkan bahwa pemeriksaan nilai DMF-T awal didapatkan 74 gigi dengan adanya karies. Setelah dilakukan perawatan dengan melakukan penambalan glassionomer di klinik gigi Poltekkes Kemenkes Manado tidak didapati lagi adanya karies pada gigi siswa dengan nilai Filling (tambalan baik) menjadi 76.

c. Distribusi frekuensi pemeriksaan nilai def- $t$ awal dan akhir dapat dilihat pada tabel 5 dibawah ini :

Tabel.5 Distribusi frekuensi niali def-t awal dan akhir

\begin{tabular}{clcc}
\hline \multirow{2}{*}{ No } & Nilai de-f & N & Persentase \\
\cline { 2 - 4 } & Sebelum & & \\
\hline 1 & $\mathrm{~d}$ & 48 & 43.6 \\
2 & $\mathrm{e}$ & 62 & 56.4 \\
3 & $\mathrm{f}$ & 0 & 0 \\
& Sesudah & & \\
\hline 1 & $\mathrm{~d}$ & 0 & 0 \\
2 & $\mathrm{e}$ & 62 & 56.4 \\
3 & $\mathrm{f}$ & 48 & 43.6 \\
\hline & Total & 110 & 100 \\
\hline
\end{tabular}

Dari tabel 5 diatas menunjukkan bahwa pemeriksaan nilai def-t awal didapatkan 48 gigi susu yang karies dan 62 gigi susu yang goyang maupun persistensi yang harus segera dilakukan tindakan penambalan dan pencabutan. Setelah dilakukan perawatan di klonik gigi Poltekkes Kemenkes Manado, gigi susu yang karies maupun persistensi telah dilakukan tindakan penambalan dan pencabutan agar tidak menimbulkan masalah kesehatan gigi dan mulut dikemudian hari. d. Hasil uji statistik pretest posttest pengetahuan dan indeks OHI-S

Tabel 6. Hasil analisis metode sekolah binaan terhadap pengetahuan siswa

\begin{tabular}{cccccc}
\hline & $\mathrm{N}$ & Ties & $\begin{array}{c}\text { Mean } \\
\text { Rank }\end{array}$ & $\begin{array}{c}\text { Sum } \\
\text { Of } \\
\text { Rank }\end{array}$ & $\begin{array}{c}\text { Asymp. } \\
\text { Sig. (2- } \\
\text { tailed) }\end{array}$ \\
\hline $\begin{array}{ccccc}\text { Pre } \\
-\end{array}$ & 30 & 0 & 15.50 & 465.00 &, 000 \\
Post & & & & & \\
\hline
\end{tabular}

*uji wilcoxon

Berdasarkan data diatas telah dilakukan uji normalitas Shapiro Wilk hasilnya data tidak terdistribusi dengan normal oleh karena nilai Sig $<0,05$. Dengan demikian dilakukan uji Wilcoxon yang merupakan metide statistic non parametric. Hasil Uji didapatkan nilai Asymp. Sig(2 tailed $)<0,000$ berarti ada pengaruh dengan metode sekolah binaan terhadap tingkat pengetahuan siswa tentang kesehatan gigi dan mulut.

\section{PEMBAHASAN}

Melaksanakan program UKGS, dibutuhkan metode agar kegiatan UKGS lebih efektif dan efisien untuk mencapai tujuan yang telah ditetapkan. Metode pelaksanaan UKGS dapat berupa UKGS tahap 1, UKGS tahap 2 dan UKGS tahap $3^{(4)}$. UKGS tahap 1 yaitu tentang pelayanan kesehatan gigi dan mulut untuk murid SD dan MI yang belum terjangkau oleh tenaga dan fasilitas kesehatan gigi. UKGS tahap 2 yaitu tentang pelayanan kesehatan gigi sudah terjangkau fasilitas kesehatan gigi. UKGS tahap 3 yaitu pelatihan guru pembina UKGS dan dokter kecil tentang pengetahuan kesehatan gigi dan mulut sudah dilaksanakan. Hasil wawancara responden menunjukkan bahwa program kesehatan gigi dan mulut pada anak sekolah dasar dilakukan melalui UKGS hanya dilakukan setiap 1 kali dalam tahun sekali, keterbatasan sarana pasarana dan tenaga, sehingga perlu adanya 
inovasi pengembangan program kesehatan gigi di sekolah melalui revitalisasi UKGS ${ }^{(14)}$.

Secara deskriptif hasil penelitian menunjukkan adanya perubahan tingkat pengetahuan pada siswa, dimana untuk sebelum perlakuan masih ditemukan siswa dengan tingkat pengetahuan kurang serta ditemukan tingkat pengetahuan yang baik. Sesudah dilaksanakan metode sekolah binaan terjadi perubahan sebaliknya kearah positif yaitu tidak ditemukan lagi katagori kurang, tetapi terjadi perubahan ke katagori baik dari yang sebelum perlakuan. Adanya perubahan ini didukung dengan hasil uji statistik pada tabel 3 didapatkan nilai $p=0,000<0,005$ berarti ada pengaruh dengan metode sekolah binaan terhadap tingkat pengetahuan siswa.

Materi kesehatan gigi disampaikan dalam pembahasan kebersihan pribadi di kelas satu. Hal ini penting disampaikan sejak dini karena anak sekolah dasar umur 6-12 tahun masuk dalam masa kritis baik bagi pertumbuhan gigi geliginya juga bagi perkembangan jiwanya. Materi yang disampaikan sesuai dengan kompetensi dasar mata pelajaran Penjaskes Kementerian Pendidikan dan Kebudayaan. Menurut Kementerian Pendidikan dan Kebudayaan (2013) kompetensi dasar mata pelajaran Penjaskes adalah mengetahui bagianbagian tubuh manusia dan kegunaannya, mengetahui dampak jangka pendek melakukan aktivitas fisik, mengetahui cara menjaga kebersihan diri yang meliputi kebersihan badan, gigi, kulit, kuku, telinga, rambut, hidung, tangan dan kaki serta pakaian ${ }^{(\mathbf{1 0})}$.

Pelayanan kesehatan merupakan kegiatan yang meliputi preventif dan kuratif. Kegiatan preventif bertujuan memelihara kesehatan yang bersifat umum dan khusus, penjaringan kesehatan. Kegiatan kuratif merupakan kegiatan penyembuhan dan pemulihan, kegiatan yang dilakukan berupa pengobatan terhadap suatu penyakit. Kegiatan pelayanan kesehatan dalam program UKGS meliputi pemeriksaan dan penjaringan kesehatan gigi dan mulut peserta didik, perawatan kesehatan gigi mulut dan rujukan kesehatan gigi mulut
(Kementerian Kesehatan, 2012). Dari hasil penelitian didapati bahwa pada indeks def-t, terdapat 56 gigi berlubang dan 62 gigi dengan indikasi pencabutan yang harus segera mendapatkan perawatan mengingat kegiatan UKGS dilaksanakan hanya setahun sekali. Setelah dilakukan metode sekolah binaan, para siswa dirujuk ke klinik jurusan keperawatan gigi untuk mendapatkan perawatan penambalan dan pencabutan gigi susu agar tidak terjadi masalah kesehatan gigi dan mulut dikemudian hari.

Untuk indeks DMF-T untuk kategori D (decay) terdapat 74 dan kategori $\mathrm{F}$ (filling) hanya terdapat dua, setelah dilakukan metode sekolah binaan siswa dirujuk ke klinik Jurusan Kesehatan Gigi untuk mendapatkan perawatan penambalan yang dilakukan oleh mahasiswa keperawatan gigi dengan pendampingan oleh instruktur/dosen sehingga nilai Decay menjadi 0 dan nilai filling (tambalan baik) menjadi 76. Pada ini ditemukan nilai missing tidak ada dan penambalan gigi hanya 2 , hal ini dikarenakan responden masih anak - anak dan belum mengetahui pentingnya menjaga kesehatan gigi dan mulut. Padahal salah satu tujuan Oral Health yang telah disepakati WHO, FDI, dan IADR untuk penyakit karies gigi di Indonesia adalah mengurangi komponen D (Decay) pada usia 12 tahun (Hobdell M, at al). Sehingga perlu adanya inovasi pengembangan program kesehatan gigi di sekolah melalui revitalisasi UKGS. Revitalisasi UKGS dapat dilakukan melalui upaya inovatif dengan Kegiatan UKGS penjaringan kesehatan gigi dan mulut, dilanjutkan dengan penanganan kasus sesuai kompetensi dan rujukan ke kampus JKG atau ke Puskesmas, serta pelatihan dokter kecil.Tingkat kebersihan gigi dan mulut sebelum dilaksanakan metode sekolah binaan dengan kriteria sedang sebanyak 9 responden (30\%), buruk sebanyak 21 responden $(70 \%)$. Setelah diberikan perlakuan dengan metode sekolah binaan, didapatkan persentase dengan kategori baik sebanyak 23 responden $(76,7 \%)$, sedang sebanyak 7 responden $(23,3 \%)$ dan tidak ada responden dalam kategori buruk. Hal ini telah di uji statistik menggunakan uji Wilcoxon pada tabel 18 dengan hasil Uji 
didapatkan nilai Asymp. Sig(2 tailed) $<0,000$ berarti ada pengaruh dengan metode sekolah binaan terhadap indeks kebersihan gigi dan mulut (OHI-S) siswa.

\section{KESIMPULAN}

1. Implementasi model pengembangan institusi melalui UKGS Binaan layak sebagai program pelaksanaan PKL mhs Jurusan Kesehatan Gibi Poltekkes Manado.

2. Implementasi modul pengembangan institusi melalui UKGS binaan efektif meningkatkan pengetahuan, sikap dan keterampilan dokter kecil di sekolah SD Katolik Santa Theresia.

3. Implementasi model pengambangan isntitusi melalui UKGS efektif meningkatkan kesehatan gigi dan mulut siswa SD.

\section{SARAN}

1. Bagi Siswa

Agar selalu memelihara kebersihan gigi dan mulut dengan cara menyikat gigi minimal dua kali sehari setelah makan pagi dan sebelum tidur malam, mengurangi makanan yang manis dan mudah melekat pada gigi.

2. Bagi Sekolah

Agar selalu menjalin kerjasama yang baik dengan institusi kesehatan gigi khususnya Jurusan Kesehatan Gigi Poltekkes Kemenkes Manado.

3. Bagi Politeknik Kesehatan Manado

Terjalinnya kerjasama dengan SD St. Theresia Manado sebagai sekolah binaan, dan mahasiswa Jurusan Keperawatan Gigi dapat melaksanakan praktek lapangan sehingga menciptakan peningkatan derajat kesehatan gigi dan mulut siswa sekolah dasar.

\section{DAFTAR PUSTAKA}

1. Alamsyah, Manajemen Pelayanan Kesehatan, Nuha Medika, Yogyakarta. 2011

2. Daryanto, Evaluasi Pendidikan, Rineka Cipta, Jakarta. 2012

3. Husaini Usman, Manajemen Teori, Praktik dan Riset Pendidikan, Bumi Aksara, Jakarta. 2011

4. Hobdel M, at al. Global Goals for Oral Health 2020. International Dental Journal. 2003 ; 53, 285-288

5. Kementerian Kesehatan Republik Indonesia, Pedoman Usaha Kesehatan Gigi Sekolah (UKGS), Direktorat Jenderal Bina Upaya Kesehatan, Jakarta. 2012

6. Kwan, S.Y. L., dkk. Healt Promoting Schools An Opportunity for Oral Health Promotion. Buletin of The World Health Organization. 2005

7. Lutchman, C., Evans, D., Ghanem, W., Maharaj, R., 7 Fundamentals of an Operationally Excellent Management System, CRC Press, New York. 2015

8. Mecatti, F., Conti, Pier L., and Ranalli, Maria G., Contributions to Sampling Statistics, Springer, Switzerland. 2014

9. Moniz, Richard J., Practical And Effective Management of Libraries: Integrating Case Studies, General Management Theory And Self Understanding, Chandos Information, USA. 2010

10. Pani, Sharat C., Knowlaedge and Attitude of Saudi Teachers of Students With Attention-Deficit Hyperacrivity Disorder Towards Traumatic Dental Injuries, Dental Traumatology 30, June 2013

11. Petersen P.E., Promoting Oral Health of Children Through Schools-ResultsFrom a WHO Global Survey 2012, Community Dental Health 30, 2013

12. RISKESDAS. Badan Penelitian dan Pengembangan Kesehatan RI. Jakarta 2013.

13. Robinson, Peter G, Developing a PersonCentred Approach to Oral Health,Dentine Hypersensitivity Elsevier, UK 2015.

14. Santoso B T, Nyoman Gejir, Diyah Fatmasari. Information System Monitoring Model Implemented in School Health 
Dental Unit. ARC Journal of Dental Science. 2017;2(4) 